\title{
What is yet to come? Three propositions on the future of educational research as a common good
}

\author{
Mathias Decuypere \\ Laboratory for Education and Society, University of Leuven, Belgium \\ To cite this article: Mathias Decuypere (20I5). What is yet to come? \\ Three propositions on the future of educational research as a common \\ good, European Educational Research Journal, I4:I, 44-48. DOI: \\ I0.1I77/|474904|I4565I57
}

To link to this article: $\underline{h t t p: / / d x . d o i . o r g /|0.1 / 77 / / 474904| \mid 4565 / 57 ~}$

\begin{abstract}
This paper offers some explorative notes accompanying the issues I addressed in the journal's moot, which took place at the ECER 2014 conference (Porto, September I-5). The notes that follow are explicitly written through the eyes of an emerging researcher, and offer three propositions regarding the future of educational research. These three propositions, which could be conceived as focal issues that I deem of paramount importance regarding the future of educational research, are centered around one general conviction, that is, that education in general and educational research in particular should be conceived in terms of being a common good - something of and for everybody, but not owned by anybody in particular. Based on this conception, the first proposition advances the importance of domain-oriented research next to approach-oriented research; the second proposition offers some thoughts on how to recompose the current publishing model; and the third proposition advances the idea that the European Conference on Educational Research itself could perhaps be partly conceived as and designed in terms of being a moot as well.
\end{abstract}

\section{Keywords}

Educational research, university, commons, publishing, conferences

The subject that the editors of the European Educational Research Journal (EERJ) have chosen for this year's moot is a tremendously important one, albeit it is a tremendously difficult one to talk about as well. What is yet to come? What will the future of educational research entail? This question, I think, can only be answered if one is in possession of something peculiar: either one is in 
possession of this mysterious thing termed 'professional experience' - and I suspect one would need a considerable amount hereof in order to even begin to answer this question sensibly - or one is in possession of a crystal ball - which would make the question unfruitfully mute. Since I am, as an emerging researcher, in possession of neither of these two things, I grant myself the freedom to reframe this question somewhat in order to arrive at a possible answer: in what follows, I am not going to make any predictions about this future. Rather than that, I will offer three propositions that I deem to be of paramount importance vis-à-vis the future of educational research. These three propositions are all centred around one general conviction, namely that educational research should be thought of in terms of being a common good. As is well known, recently the educational field has witnessed growing and booming neoliberal attempts seeking to appropriate and privatize many aspects of what education is or could be. My three propositions, on the contrary, are embedded in quite another conception of what education in general and educational research in particular should be, that is to say, a common good: something of and for everybody, but not owned by anybody in particular. I invite the reader to read my three propositions in this general, commoning, vein - even though I am fully aware of the normativity behind this position. I do not consider this normativity as a weakness, however. After all, if emerging researchers apprehend one thing quite fast, it is the observation that education(al research) is, fortunately, heavily embedded in norms and values, pertaining to questions such as how to conceive of future generations in particular and how to approach and compose our (future) world in general. As a disclaimer, I furthermore wish to add that the three propositions that follow do not have the intention to be exhaustive. Rather than that, they give an overview of what I deem to be focal issues for the future of educational research: firstly, the way in which we approach our research discipline itself; secondly, the way in which we publish; thirdly, the way in which we could conceive of conferences on educational research.

\section{First proposition: Approach- and domain-oriented research}

In order to advance my first proposition, I would like to propose a distinction between approachoriented research on the one hand and domain-oriented research on the other. Approach-oriented research is the kind of research the educational field is most familiar with. Academics then start from a particular approach and investigate, based on this approach, different aspects of the educational field. Scrutinized aspects include, for instance, neoliberal policy developments, multiculturalism or the internationalization of higher education on a macro level, or teaching efficiency, pupils' wellbeing and educational attainment on a micro level. Although - let me be very clear on this point - there is nothing wrong with this conception, it generally tends to lead to a targeting of the educational research field. That is to say, educational researchers tend to investigate such aspects by means of approaches that are most of the time external to the educational discipline, be these approaches psychological, philosophical, sociological, economical or something other. This results, one could state, in research that goes from the outside inwards: based on a particular approach (acting as a framework), educational researchers often target (particular aspects of) the educational field, witnessed in nomenclatures such as 'sociology of education', 'philosophy of education', 'psychology of education', and so on.

Through the eyes of an emerging researcher, however, the dominance of such approach-oriented research is somewhat surprising and sometimes even puzzling. Many emerging researchers do not enter into a research career in education because they are primarily interested in (one of) these approaches. Rather, one often enters the field because one is genuinely interested in, fascinated with or concerned about a particular dimension of or evolution in the educational field itself. Perhaps this is one of the reasons why many emerging researchers find it so hard to answer questions as 'Are you a sociologist?' or 'Are you a psychologist?'. Could it be that they rather 
consider themselves as being educationalists, hence referring to something like an internal discipline? Could it be that, given this dominance of approach-oriented research and despite all contemporary talk about interdisciplinarity, we should equally (again) be in search of what our own discipline constitutes precisely? It is in view of such questions that I would like to advance the proposition that in the coming years, we not only conduct approach-oriented research on education but that we equally search for ways so as to put educational research more centre-stage. I use the latter term here to designate that particular kind of research that could be considered to be domain- rather than approach-oriented, and as such going from the inside out, instead of from the outside in: starting from the educational domain, instead of from an outside approach by means of which we investigate the field.

In a sense, and as was rightly noted during the moot of the 2014 ECER conference, this implies a future that is partly driven from behind, and framing this first proposition likewise equally refers to what was, at the very inception of the university, denoted as an universitas: an association of academics and students, in which the traditional threefold of research, education and service provision was deeply intertwined instead of steeply demarcated (De Ridder-Symoens, 2003). Perhaps it is especially by (re-)turning to this original meaning of the university that we can find ways in which to integrate an educational dimension into our research as well, without having to be obliged to make a clear-cut separation between these three functions and by means of which we can search for ways so as to render these aforementioned external approaches educational themselves. This would, then, imply a search for educational sociologies, educational psychologies, educational economics, and so on. These thoughts are highly related towards conceptualizing education in general and educational research in particular as being a common good, and are undoubtedly in need of an exploration of alternative ways of doing research (e.g. collective research with students, professors and the larger educational field instead of secluded research); of alternative vocabularies that have not originated in or been appropriated by other domains (e.g. formation/Bildung instead of learning, care/passion instead of professionalism, interest instead of motivation); and conclusively of alternative ways to conceive of the general nature of academic activities themselves (as resultants of commoning activities for instance, instead of originating from disinterested and objective research; Callon et al., 2009; Simons and Masschelein, 2014).

\section{Second proposition: Rethinking publishing and valorization models}

If we conceive of academic activities as being commoning activities, that is, activities that at least have the purpose to make something common, it could be argued that the current publishing format, where privatizing and appropriating logics prevail, is rightly drawing to a close: instead of making research results public, we still willingly renounce copyright to multinational publishing companies (e.g. Nóvoa, 2014). The rising alternative, that is, open access (OA) publishing, is absolutely true to commoning premises in the sense that it attempts to freely disclose research results to each and all. Currently, however, we are witnessing mechanisms by means of which this commoning alternative is immediately being re-appropriated anew. For instance, at present fee-based OA journals are proliferating, again requiring an unfruitful investment of (primarily) public tax money in order to make research public. Especially in this digital age, this no longer seems an absolute inevitability - if we rethink the way we valorize our research, that is. It is, therefore, urgently necessary that we start to rethink not only this publishing model, but equally the way in which we, as researchers, deal with the general manner in which we make our research public as well. What is valuable? Where is it being made valuable? Furthermore, should we focus on text-based research articles solely, or are there in the future maybe also other possibilities to pursue? 
Such questions, I think, are especially poignant for many emerging researchers who currently struggle with the established publication model in which primacy is given to text-based journal articles - a few illustrating figures or tables notwithstanding. Indeed, in the digital times in which we are living, it perhaps no longer makes sense to limit the valuation of research results to the classic journal format solely. Could we, for instance, think of ways in which to value movies or visuals not as being mere illustrations, but rather as research objects in their own right? As was noted during the moot, the future is not something awaiting but happening right now. Indeed it is: many creative attempts in this vein are already being pursued currently (see also last year's moot: Hoveid et al., 2014), and perhaps especially amongst emerging researchers. Alternative manners of making research results public are at the moment simply not valorized enough, however: even the OA model is still largely based on the valorization of textual matters. It is maybe not very revolutionary to state that websites could play a crucial role in that respect, but perhaps time has come to state that they should.

All this raises some very challenging questions, not only with respect to the format(s) in which we publish but equally pertaining to review procedures. How, for instance, are we going to review such alternative attempts at making things public? There is a tremendous amount of work to be done here, work that should perhaps primarily be effectuated by the established generation of researchers. After all, if anybody can determine what is deemed to be valuable and what is not, it is this established generation. This is not to say that emerging researchers just need to stand comfortably at the sidelines: since they - still, somehow - have some more time and space to do this than the established generation, especially this emerging generation needs to take the lead in continuing with experimenting with other publication formats: not only text, but equally visuals, movies, websites, and so on. Hence, this second proposition constitutes a call for both generations to mutually engage in making commoning activities in general public, and to experiment with the issues sketched and the questions raised here in particular.

\section{Third proposition: Mooting our conferences}

My third and last proposition is directed at how we could think differently and more inclusively about the way in which we organize our conferences in the future. Conferences constitute extremely valuable moments in which we can present our research, exchange ideas and engage in debate. In this sense, conferences have an enormous potential with respect to making the educational domain a common domain. However, there might be ways in which we could exploit this potential more fully, particularly with regards to how we organize these conferences precisely. Especially for emerging researchers, and partly due to reasons I sketched in my first proposition, organizing conferences - and I take the European Conference on Educational Research (ECER) as the prime example here - in separated networks with semi-permeable borders sometimes feels rather artificial and gives way to trepidation: Which network to 'pick' as an emerging researcher? Is sticking to one prime network the viable option, or should one happily switch between presentations in different networks and based on short abstracts? These are no trivial questions, since they partly define the people one gets acquainted with, which kind of research one can present and which not, and the way in which future research lines will be incorporated in existing networks or not. (Do they fit? Are they in need of a new network?)

With these thoughts in mind, perhaps we could partly reconceptualize educational conferences such as the ECER and give them a more commoning and 'mootish' touch, in the sense that it might equally be worthwhile to focus to a greater extent on common issues that unite us, rather than on approaches that divide us. Of course, such initiatives are already partly proliferating and being explored (e.g. this very EERJ moot; the recently founded network 30). However, it might be 
valuable to explore this issue-oriented approach more fully, which would be a third approach to educational research: this would neither constitute domain-oriented (although closely related) nor approach-oriented research, but rather an issue-oriented endeavour, in which a diverse and potentially divided public is centred around a particular educational issue that unites diverse spokespersons and to which there is no single, unequivocal answer (Dewey, 1954; Latour, 2005). This would require a new approach to how we conceive of conferences: conceiving of the ECER as a moot could, for instance, imply that we reconceive at least partly its structure, not solely organizing it in terms of networks, but equally in terms of issues that are being addressed by many, but to which nobody has a clear-cut answer. The ECER, then, could be a place to share research results in which researchers are only some of the possible spokespersons; a place in which different theories and research results could be made public and common in joint cooperation with other spokespersons (teachers, policy makers, students, etc.); a place to take the potential of educational research as public interventions more centre-stage. Although this constitutes no plea for a total abandonment of networks where research results are shared with likeminded people, perhaps it would constitute a good idea to equally abandon our safe havens once in a while, and invite other spokespersons to join the dialogue, in short, to stay true to the very meaning of what a moot is, can, or should be.

\section{References}

Callon M, Lascoumes P and Barthe Y (2009) Acting in an Uncertain World. An Essay on Technical Democracy. Cambridge, MA/London: MIT Press.

De Ridder-Symoens H (ed.) (2003) A History of the University in Europe. Volume 1: Universities in the Middle Ages. Cambridge, UK: Cambridge University Press.

Dewey J (1954). The Public and its Problems. New York: Holt.

Hoveid MH, Keiner E and Seddon T (2014) A 'moot' for educational research in Europe? European Educational Research Journal 13(2): 130-142.

Latour B (2005). From Realpolitik to Dingpolitik or how to make things public. In: Latour B and Weibel P (eds) Making Things Public. Atmospheres of Democracy. Cambridge, MA: MIT Press, pp.14-43.

Novóa A (2014) What is educational research for? In: ECER 2014 keynote address.

Simons M and Masschelein, J (2014) “This Truth That I Say to You, Well, You See It in Myself”: On research as education | As philosophy | As a way of life. In: Reid A, Hart E and Peters M (eds) A Companion to Research in Education. Dordrecht, The Netherlands: Springer, pp.83-95.

\section{Author biography}

Mathias Decuypere is a PhD researcher of the Flemish Research Foundation (FWO) and affiliated to the Laboratory for Education and Society (University of Leuven). In his doctoral research, he investigates how the daily functioning of the university in general and its inhabiting academics in particular is composed of both human and non-human actors, and this by means of a sociomaterial and ethnographic approach. 